\title{
ISOLATION AND DETERMINATION CARPAINE ALKALOID IN PAPAYA (CARICA PAPAYA L.) LEAF EXTRACT BY THIN-LAYER CHROMATOGRAPHY SCANNER
}

\author{
YASMIWAR SUSILAWATI ${ }^{1,2^{*}}$, NYI MEKAR SAPTARINI ${ }^{3}$, ZELIKA MEGA RAMADHANIA ${ }^{2}$, ELI HALIMAH ${ }^{4}$, NAILAH \\ NURJIHAN ULFAH ${ }^{2}$
}

${ }^{1}$ Herbal Study Center, Faculty of Pharmacy, Padjadjaran University, Jalan Raya Bandung-Sumedang KM 21, Jatinangor, West Java,

Indonesia, 2Department of Biology Pharmacy, Faculty of Pharmacy, Padjadjaran University, Jalan Raya Bandung-Sumedang KM 21, Jatinangor, West Java, Indonesia, ${ }^{3}$ Department of Pharmaceutical Analysis and Medicinal Chemistry, Faculty of Pharmacy, Padjadjaran University, Jalan Raya Bandung-Sumedang KM 21, Jatinangor, West Java, Indonesia, ${ }^{4}$ Department of Pharmacology and Clinical Pharmacy, Faculty of Pharmacy, Padjadjaran University, Jalan Raya Bandung-Sumedang KM 21, Jatinangor, West Java, Indonesia

"Email: yasmiwar@unpad.ac.id

Received: 20 Aug 2021, Revised and Accepted: 02 Oct 2021

\section{ABSTRACT}

Objective: This research was conducted to isolate the alkaloid carpaine by chromatography method and to determine it quantitatively by Thin Layer Chromatography Scanner.

Methods: Dried leaves were macerated with ethanol $70 \%$ and fractionated with dichloromethane. Isolation of carpaine alkaloid from the dichloromethane fraction was carried out by column chromatography and preparative thin-layer chromatography according to the $\mathrm{R}_{\mathrm{f}}$ value in Thin Layer Chromatography (TLC) after exposure by Dragendorff reagent.

Results: The content of carpaine alkaloid was $7.5 \mathrm{mg}$ with $\mathrm{R}_{\mathrm{f}} 0.58$ and dichloromethane: methanol (9.2:0.8) as eluent. Validation showed the linearity $\left(\mathrm{R}^{2}\right) 0.9988$, the limit of detection(LOD) was $0.05 \mathrm{ppm}$, the Limit of Quantification (LOQ) was $0.19 \mathrm{ppm}$, the recovery from $98.93-102.43 \%$, and the $\%$ coefficient of variation was $0.16 \%$.

Conclusion: Carpaine alkaloid in papaya leaf extract was $10.52 \%$.

Keywords: Carica papaya, Papaya leaf, Carpaine alkaloid, Validation method, TLC scanner

(c) 2021 The Authors. Published by Innovare Academic Sciences Pvt Ltd. This is an open access article under the CC BYlicense (https://creativecommons.org/licenses/by/4.0/) DOI: https://dx.doi.org/10.22159/ijap.2021.v13s4.43867 Journal homepage: https://innovareacademics.in/journals/index.php/ijap

\section{INTRODUCTION}

Papaya (Carica papaya L.) comes from the family Caricaceae. This plant is cultivated in almost all subtropical and tropical countries such as South America, India, Phillippines and Indonesia. Almost all parts of the papaya plant have medicinal properties [1]. Papaya leaves extract have properties as hematopoietic, antimalarial, antifungal, anti-HIV-1, hypoglycemic, anti-inflammatory, antimicrobial, anti-tumor, immunomodulatory, hepatoprotector, and anti-thrombocytopenic activity [2-10]. In addition, papaya leaves can significantly increase platelet counts and increase the number of red blood cells [11] and showed analgesic activity in mice compared to aspirin [12]. Papaya leaves contain alkaloids carpaine, dehydrocarpaine I and II, pseudocarpaine, choline, carposide, flavonols, benzylglucocinolate, papain, tannins, vitamin C, and E [13]. The major component of papaya leaves is carpaine alkaloid. This compound reported can reduce blood pressure, antitumor and antiplasmodial activity [14]. In relation to lowering blood pressure, it was reported that carpaine showed a direct effect on the myocardium, where this effect was thought to be related to the macrocyclic dilactone structure, a possible cation chelating structure [15]. The isolated carpaine is able to maintain mouse platelets up to $555 \pm 85.17 \times 109 / \mathrm{L}$ which has been induced by busulfan for $20 \mathrm{~d}$ with a dose of $200 \mathrm{mg} / \mathrm{kg}$ papaya leaf extract containing $2 \mathrm{mg} / \mathrm{kg}$ carpaine alkaloid [16].

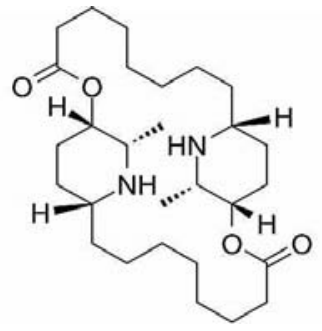

Fig. 1: Carpaine structure [17]
Carpaine alkaloid found with molecular docking has the potential to be antiviral dengue because they have interactions with Thr413 amino acid residues against RNA-dependent RNA polymerization in dengue viruses [18].

The research of Wang et al. (2015) states that the levels of carpaine alkaloid in papaya leaves are $0.93 \mathrm{~g} / \mathrm{kg}$ by HighPerformance Liquid Chromatography (HPLC) method [19]. Chromatography is a simple method that can be used to identify secondary metabolites in plants, including alkaloids [20]. Densitometry method with TLC scanner has been used at research of alkaloid compounds in Chelidonium majus L. plants which are capable of detecting many samples at the same time [21]. The densitometry method is simpler than HPLC in determining the level of identity compounds in an extract. This method has the advantages like being more effective in preparation and cost-efficient, even though it has a less sensitive sensitivity compared to HPLC. Determination of levels in extracts with TLC scanner is needed validation to determine a method that can use as the determination requirements. Therefore, this study aimed to isolate and determine carpaine alkaloids from papaya leaf extract Carica papaya L. using the TLC densitometry method.

\section{MATERIALS AND METHODS}

\section{Plant material}

Papaya (Carica papaya L.) leaves taken from botanical garden Manoko Lembang, Bandung, West Java, Indonesia. The plant identification was determined in the Taxonomy Laboratory, Department of Biology, Faculty of Mathematics and Natural Sciences, Universitas Padjadjaran, Indonesia.

Chemical materials

All solvents and chemicals used to prepare Dragendorff, Mayer, and Liebermann-Burchard reagents had an analytical grade purchased from Merck, including silica gel $\mathrm{GF}_{254}$. 


\section{Isolation of carpaine alkaloid}

Two kilograms of dried leaves were macerated with $70 \%$ ethanol at room temperature and protected from light. This extraction was repeated three times until most of the chemical components were extracted. All extracts were evaporated at $50{ }^{\circ} \mathrm{C}$ and $60 \mathrm{rpm}$ with a rotary evaporator. The concentrated extract was dissolved in $500 \mathrm{ml}$ of $2 \%$ hydrochloride acid ( $\mathrm{pH}$ 2.0-3.0), then extracted with $n$-hexane to remove fatty acids and other non-polar compounds. The acid fraction was adjusted to $\mathrm{pH}$ 8.0-9.0 with ammonia solution and extracted with dichloromethane. The dichloromethane fraction was evaporated with a rotary evaporator at 50 ${ }^{\circ} \mathrm{C}$. The dichloromethane fraction was dried and then placed in the put into column chromatography and eluted gradient with a solvent mixture of $n$ hexane: ethyl acetate (5: 5) to $(0: 10)$ and continued by dichloromethane: methanol $(0: 10)$ to $(9: 1)$. Each sub-fractions were monitored by TLC using dichloromethane: methanol (9:1) as mobile phase; then the eluted plates were exposed to Dragendorff reagent. The sub-fractions contained carpaine alkaloid were purified by preparative-TLC.

\section{Validation method [22]}

\section{Stock preparation}

Five milligrams of carpaine alkaloid dissolved with acetone $0.5 \mathrm{ml}$ in Eppendorff tube then diluted to 5 various concentrations $(312.5,625$, $1250,2500$, and $5000 \mathrm{ppm})$.

\section{Linearity, LOD, and LOQ}

The standard solution was diluted showed on the TLC plate, then eluted $10 \mathrm{~cm}$ long and measured in the area at the maximum wavelength.

\section{Accuracy}

Each standard concentration showed on the TLC plate then eluted $10 \mathrm{~cm}$ long and measured in the area at the maximum wavelength and repeat twice.

\section{Precision}

Each standard concentration showed on the TLC plate then eluted 10 $\mathrm{cm}$ long, measured in the area at the maximum wavelength, and repeated twice.

\section{Carpaine analysis in papaya leaf extract}

Papaya leaf extract was weighed $3 \mathrm{mg}$ and dissolved with $1 \mathrm{ml}$ acetone, repeated twice. Each sample solution was placed in the TLC plate, then measured by a TLC scanner.

\section{RESULTS}

This plant was taxonomically determined at Plants Taxonomy Laboratorium, Faculty of Mathematics and Natural Sciences, Universitas Padjadjaran as Carica papaya L. of the family Caricaceae, collection-number 476/HB/01/2017.

Two kilograms of dried papaya leaves were macerated with $70 \%$ ethanol and the yield was $18.75 \%$ or $375 \mathrm{~g}$. A total of $300 \mathrm{~g}$ of concentrated extract were fractionated with $n$-hexane and dichloromethane. Then, each fraction was obtained at $11.65 \mathrm{~g}$ $(3.89 \%)$ and $13.67 \mathrm{~g}(4.56 \%)$, respectively. Both of these fractions were determined by TLC and a dichloromethane fraction was showed the presence of carpaine alkaloid. The dichloromethane $(13.67 \mathrm{~g})$ fraction was dried, then put into column chromatography and eluted gradient with a solvent mixture of $n$-hexane: ethyl acetate $(5: 5)$ to $(0: 10)$, then continued by dichloromethane: methanol $(0: 10)$ to $(9: 1)$. Each sub-fractions were monitored by TLC using dichloromethane: methanol (9:1) as mobile phase and the eluted plates were exposed to Dragendorff reagent. The sub-fractions contained carpaine alkaloid was CpII, which continued for further separation by column chromatography, then 8 sub-fractions were obtained. Sub-fractions 1-5 were detected of carpaine alkaloid (fig. 2).

The sub-fractions 1 to 5 were combined, then performed by preparative-TLC. Carpaine alkaloid was detected at $\mathrm{R}_{\mathrm{f}}$ value of 0.58 with dichloromethane: methanol (98:2) as mobile phase. Isolated carpaine was observed in the form of a yellow powder with a weight of $7.5 \mathrm{mg}$. Calibration curves are made in a concentration range of $312.5-5000 \mathrm{ppm}$ produced a linear regression equation $\mathrm{y}=0.3266 \mathrm{x}+54.468$ with a correlation coefficient of 0.9988 .

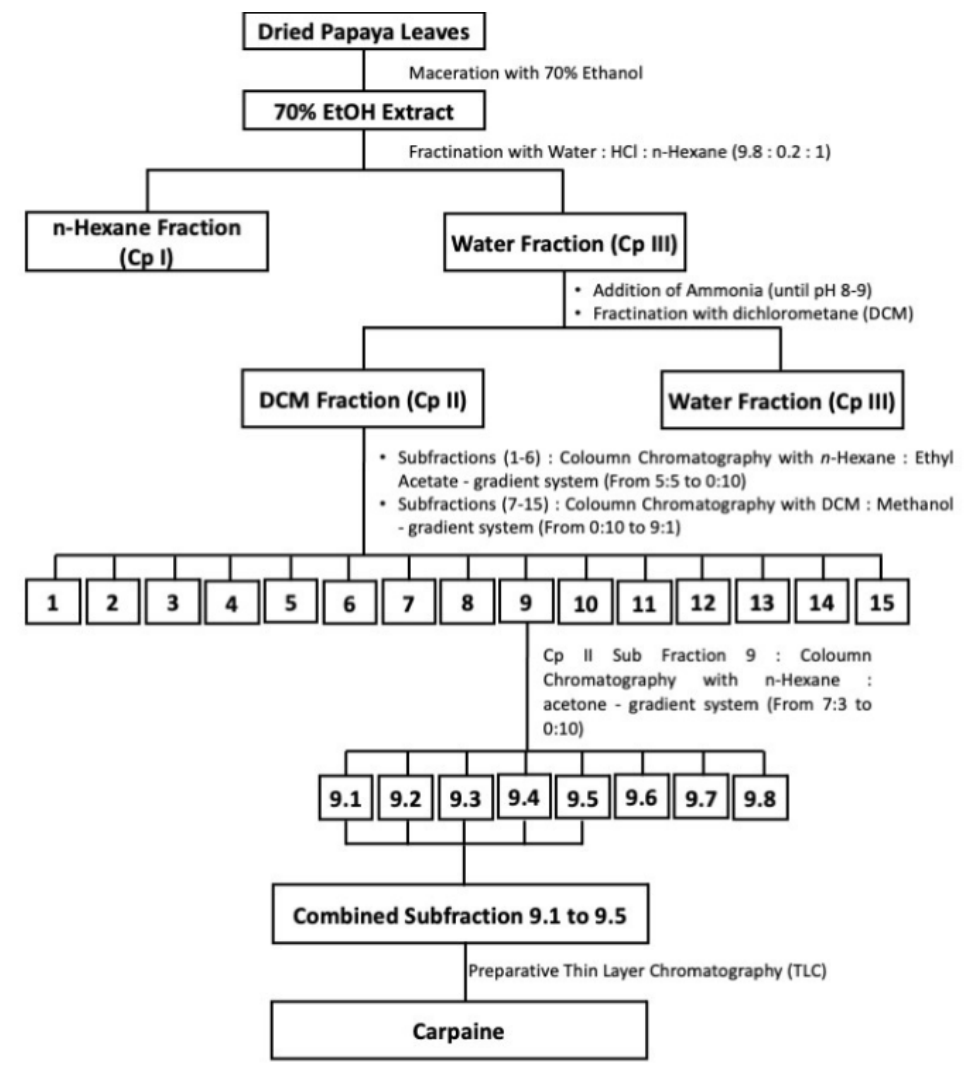

Fig. 2: Isolation process 


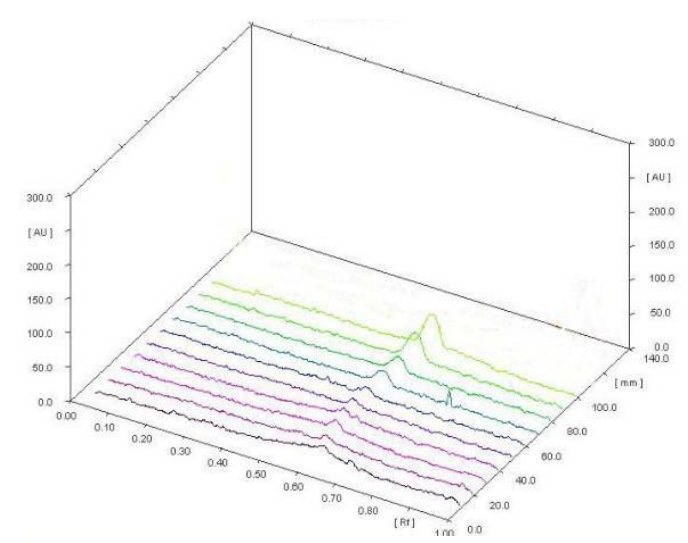

Fig. 3: Densitogram of linearity

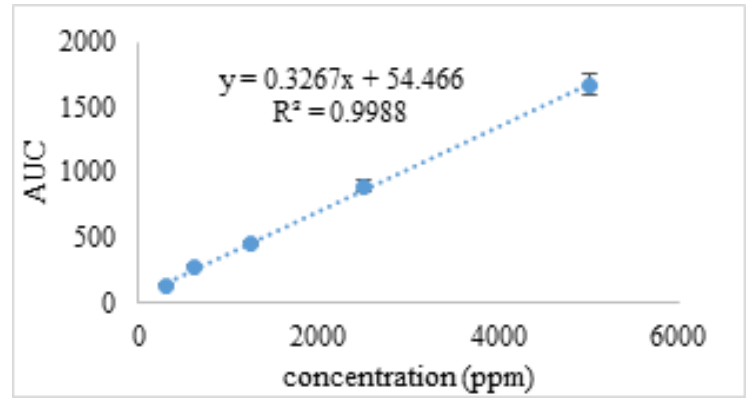

Fig. 4: Calibration curve of carpaine alkaloid

Table 1: Value of LOD and LOQ of carpaine alkaloid

\begin{tabular}{|c|c|c|c|c|c|c|}
\hline Concentration (ppm) & AUC (Y) & Peak area (Yi) & $(\mathrm{Y}-\mathrm{Yi})$ & $(Y-Y i)^{2}$ & LOD (ppm) & LOQ (ppm) \\
\hline 312.5 & 130.87 & 156.53 & -25.66 & 658.46 & 0.05 & 0.19 \\
\hline 625 & 276.89 & 258.59 & 18.297 & 334.78 & & \\
\hline 1250 & 456.66 & 462.72 & -6.058 & 36.69 & & \\
\hline 2500 & 896.45 & 870.97 & 25.482 & 649.33 & & \\
\hline \multirow[t]{2}{*}{5000} & 1675.90 & 1687.50 & -11.58 & 134.05 & & \\
\hline & & & Total & 1813.32 & & \\
\hline
\end{tabular}

Table 2: Value of accuracy of carpaine alkaloid

\begin{tabular}{|c|c|c|c|c|}
\hline Concentration (ppm) & Peak area (AUC) & Recovery (ppm) & \% Recovery & Average of \% recovery \\
\hline \multirow[t]{2}{*}{312.5} & 168.98 & 350.62 & 98.15 & 98.93 \\
\hline & 144.99 & 277.16 & 99.70 & \\
\hline \multirow[t]{2}{*}{625} & 276.89 & 681.02 & 100.20 & 99.95 \\
\hline & 238.66 & 563.97 & 99.70 & \\
\hline \multirow[t]{2}{*}{1250} & 467.21 & 1263.80 & 101.10 & 101.01 \\
\hline & 466.45 & 1261.40 & 100.91 & \\
\hline \multirow[t]{2}{*}{2500} & 897.09 & 2579.80 & 103.19 & 102.43 \\
\hline & 884.56 & 2541.60 & 101.66 & \\
\hline \multirow[t]{2}{*}{5000} & 1667.90 & 4940.00 & 98.80 & 99.11 \\
\hline & 1678.00 & 4971.10 & 99.42 & \\
\hline
\end{tabular}

Table 3: Value of precision of carpaine alkaloid

\begin{tabular}{ll}
\hline Concentration $\mathbf{( m g / m l )}$ & Peak area (AUC) \\
\hline 1.25 & 465.78 \\
1.25 & 466.98 \\
1.25 & 467.11 \\
1.25 & 468.76 \\
1.25 & 467.01 \\
1.25 & 468.90 \\
Total & 7586.40 \\
Average & 2167.60 \\
SD & 0.0017 \\
KKV & 0.16 \\
\hline
\end{tabular}


Table 4: Determination of carpaine alkaloid in papaya leaf extract

\begin{tabular}{llll}
\hline Concentration (ppm) & Peak area (AUC) sample & Assay (ppm) & Assay (\%) \\
\hline 3000 & 159.65 & 322.05 & 10.73 \\
& 155.45 & 309.19 & 10.30 \\
Average & & 315.62 & 10.52 \\
\hline
\end{tabular}

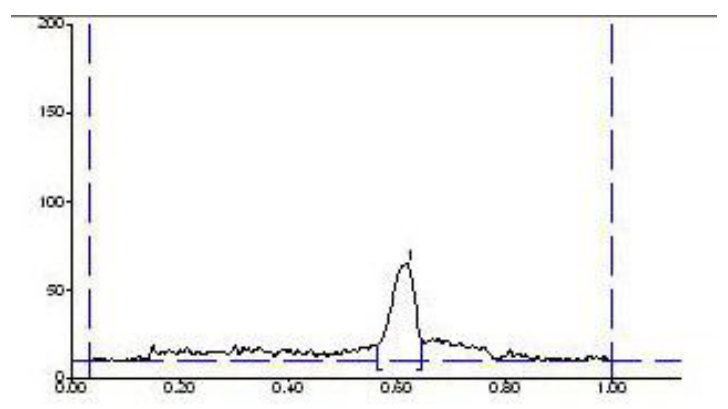

Fig. 5: Densitogram of carpaine alkaloid $R_{f} 0.62$

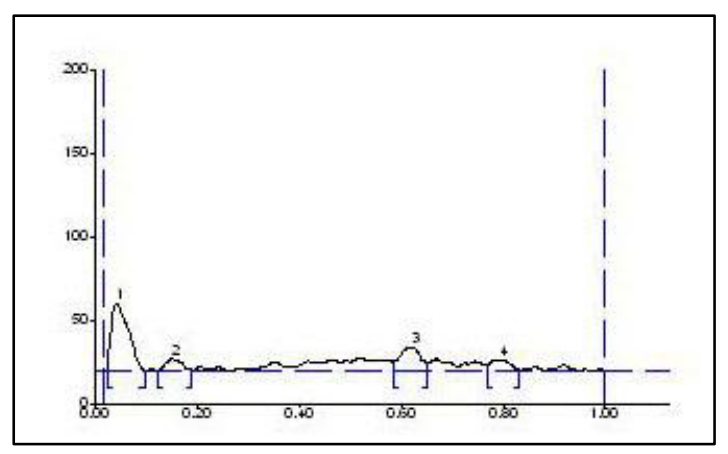

Fig. 6: Densitogram of extract sample with $R_{f} 0.62$

\section{DISCUSSION}

Plant identification was conducted to distinguish one species from all others are needed for diagnosis. The distinction between species helps characterize of genetic diversity in germplasm collections of endangered plant species [23]. The identification results showed that the plant used in the study was correct, namely Carica papaya $\mathrm{L}$.

Fig. 2 showed the isolation of carpaine alkaloid was carried out in several steps. Carpaine isolation was started by maceration using ethanol to extract all secondary metabolites. Maceration is chosen because of preserves the secondary metabolites and the high yield. The maceration principle is the slow transfer of solutes to the solvent until equilibrium [24]. Ethanol was chosen as the extraction solvent because although methanol is a better solvent to dissolve secondary metabolites, methanol is more toxic than ethanol [25]. In addition, carpaine alkaloid is soluble in ethanol and chloroform [26].

After the extract was concentrated, it was then fractionated with $n$ hexane and $2 \%$ hydrochloric acid, so that the alkaloids turned into water-soluble alkaloid salts [27]. Ammonia was added to the hydrochloric acid fraction containing carpaine alkaloid, so that carpaine alkaloid will transform to alkaline form and be dissolved in organic solvents, such as dichloromethane [27]. Dichloromethane was chosen to be easily evaporated to obtain crude carpaine alkaloid. Crude carpaine alkaloid was sub-fractionated using column chromatography so that it was separated from other compounds. Crude carpaine alkaloid from column chromatography was separated again by preparative-TLC, then purified by 2-dimensional TLC to obtain purified carpaine alkaloid as shown from a single spot.

Validation of analytical methods is an act of assessing certain parameters based on laboratory tests, to prove that these parameters meet the requirements for their use and to confirm that the analytical methods are suitable for their intended use [22]. Fig. 3 showed the responses of the TLC scanner to different concentrations of standard carpaine alkaloid as densitogram of linearity. Fig. 4 showed a coefficient correlation of 0.9988 , which met the requirement [22]. (LOD) validation method is the smallest number of analytes in the sample that can provide a significant response, while (LOQ) means the smallest number of analytes in the sample that can be quantified or meet the criteria of precision and accuracy [22]. LOD and LOQ validation method was obtained based on the results of the calibration curve of the carpaine alkaloid. The LOD value is $0.05 \mathrm{ppm}$ and the LOQ is $0.19 \mathrm{ppm}$ (table 1).

Accuracy is the closeness of a value from the measurement results to the actual value in the analyte. Accuracy results are determined by the value of \%recovery [22]. The area of the result of the calibration curve is then substituted on the equation for the calibration curve. The results of the accuracy test of carpaine alkaloid isolates indicate that the average of recoveries requirements, which were in the range of 98-102\% (table 2).

Precision is the percent value of the Coefficient of Variation (\%CV) which is calculated from the AUC value and the results of the concentration obtained. [12] Precision tested on standard solutions with a concentration of $1250 \mathrm{ppm}$ in six times replication at a wavelength of $680 \mathrm{~nm}$ and a percent coefficient of variation was obtained or $\% \mathrm{CV}$ was 0.16 (table 3 ).

The densitogram of standard carpaine alkaloid was given $\mathrm{R}_{\mathrm{f}}$ of 0.62 (fig. 5). So, to determine the concentration of carpaine alkaloid in the papaya leaf extract, the focus was on finding the Rf which was the same as the standard, which is 0.62 (fig. 6). Carpaine alkaloid concentration in $3000 \mathrm{ppm}$ papaya leaf extract was $315.62 \mathrm{ppm}$, equivalent to $10.52 \%$ (table 4 ).

Carpaine alkaloid concentration was lower than Vien's study (2017) [28]. That study obtained $63 \%$ of carpaine alkaloid in the total papaya extract that showed concentration of carpaine carpaine alkaloid in this study was lower because of the geographical and climate differences in Indonesia and Vietnam, make the nutrients in the soil would be vary causing differences content of secondary metabolites.

\section{CONCLUSION}

Carpaine alkaloid was isolated by column chromatography-TLC method and obtained $7.5 \mathrm{mg}$ of carpain isolate at Rf 0.58 with the mobile phase dichloromethane: methanol (9.2:0.8). The maximum wavelength was $680 \mathrm{~nm}$. Carpaine alkaloid in extract was obtained $10.52 \%$ with validation of linearity regression (R2) of 0.9988 , (LOD) $0.05 \mathrm{ppm}$, (LOQ) $0.19 \mathrm{ppm}$, accuracy value $98.93-102.43 \%$, and the precision value $0.16 \%$.

\section{ACKNOWLEDGEMENT}

The work is supported by the Ministry of Research and TechnologyHigher Education through the Higher Education Applied Research grant scheme (PTUPT) 2020.

\section{FUNDING}

Nil

\section{AUTHORS CONTRIBUTIONS}

All the authors contributed equally.

\section{CONFLICT OF INTERESTS}

The authors declare no conflict of interest. 


\section{REFERENCES}

1. Bhadane V, Belemker S, Mali B. The nature's potential multipurpose Gift-Papaya (Carica papaya linn.): A complete overview. AJPRD. 2014;2(1):75-82.

2. Kovendan K, Murugan K, Panneerselvam C, Aarthi N, Kumar PM, Subramaniam J, Amerasan D, Kalimuthu K, Vincent S. Antimalarial activity of Carica papaya (Family: Caricaceae) leaf extract against Plasmodium falciparum. Asian Pac J Trop Dis. 2012;2:S306-11. doi: 10.1016/S2222-1808(12)60171-6.

3. Chima N. Antifungal potencies of leaf extracts of Carica papaya on fungi implicated in soft rot of yam. Ann Food Sci Technol. 2012;13(2):202-9.

4. Khaled R, Meng-Ting L, Lin-Tao Z, Yong-Tang Z. Phytochemical screening of the polar extracts of Carica papaya Linn. and the evaluation of their anti-HIV-1 activity. JAIS. 2013;1(3):49-53.

5. Juarez-Rojop IE, Diaz-Zagoya JC, Ble-Castillo JL, MirandaOsorio $\mathrm{PH}$, Castell-Rodriguez AE, Tovilla-Zarate CA. Hypoglycemic effect of Carica papaya leaves in streptozotocin-induced diabetic rats. BMC Complement Altern Med. 2012;12:1-11.

6. Owoyele BV, Adebukola OM, Funmilayo AA, Soladoye AO. Antiinflammatory activities of ethanolic extract of Carica papaya leaves. Inflammopharmacology. 2008;16(4):168-73. doi: 10.1007/s10787-008-7008-0, PMID 18759075.

7. Anibijuwn II, Udeze AO. Antimicrobial activity of Carica papaya (pawpaw leaf) on some pathogenic organisms of clinical origin from South-Western Nigeria. Ethnobotanical Leafl. 2009; 13:850-64.

8. Otsuki N, Dang NH, Kumagai E, Kondo A, Iwata S, Morimoto C. Aqueous extract of Carica papaya leaves exhibits anti-tumor activity and immunomodulatory effects. J Ethnopharmacol. 2010;127(3):760-7. doi: 10.1016/j.jep.2009.11.024, PMID 19961915.

9. Pandit A. Ameliorative effect of leaves of Carica papaya in ethanol and antitubercular drug-induced hepatotoxicity. Br J Pharm Res. 2013;3(4):648-61. doi: 10.9734/BJPR/2013/4517.

10. Julianti T, Oufir M, Hamburger M. Quantification of the antiplasmodial alkaloid carpaine in papaya (Carica papaya) leaves. Planta Med. 2014;80(13):1138-42. doi: 10.1055/s0034-1382948, PMID 25153096.

11. Dharmarathna SLCA, Wickramasinghe S, Waduge RN, Rajapakse RPVJ, Kularatne SAM. Does Carica papaya leafextract increase the platelet count? An experimental study in a murine model. Asian Pac J Trop Biomed. 2013;3(9):720-4. doi: 10.1016/S2221-1691(13)60145-8, PMID 23998013.

12. Hasimun P, Suwendar EG, Ernasari GI. Analgetic activity of papaya (Carica papaya L.) leaves extract. Procedia Chem. 2014;13:147-9. doi: 10.1016/j.proche.2014.12.019.

13. Hossain N, Kumar PV, Wei YSA. Comparative study of phytochemical content in air dried and lyophilized Carica papaya leaves. Int J Green Pharm. 2016;10(4):220-7.

14. Tuffley B, Williams C. The pharmacology of carpaine. Aust J Pharm. 1951;52:796-8.
15. Hornick CA, Sanders LI, Lin YC. Effect of carpaine, a papaya alkaloid, on the circulatory function in the rat. Res Commun Chem Pathol Pharmacol. 1978;22(2):277-89. PMID 734216.

16. Zunjar V, Dash RP, Jivrajani $M$, Trivedi B, Nivsarkar $M$. Antithrombocytopenic activity of carpaine and alkaloidal extract of Carica papaya Linn. leaves in busulfan induced thrombocytopenic Wistar rats. J Ethnopharmacol. 2016;181:20-5. doi: 10.1016/j.jep.2016.01.035, PMID 26812680.

17. PubChem.ncbi.nlm.nih.gov/compound/Carpaine\#section=Top. Open Chem Database. 2018.

18. Radhakrishnan N, Lam KW, Norhaizan ME. Molecular docking analysis of Carica papaya Linn constituents as antiviral Agent. Int Food Res J. 2017;4(24):1819-25.

19. Wang $\mathrm{X}, \mathrm{Hu} \mathrm{C}, \mathrm{Ai} \mathrm{Q}$, Chen $\mathrm{Y}$, Wang $\mathrm{Z}, \mathrm{Ou} \mathrm{S}$. Isolation and identification carpaine in Carica papaya L. Leaf by HPLC-UV method. Int J Food Prop. 2015;18(7):1505-12. doi: 10.1080/10942912.2014.900785.

20. Kocka AB, Zalewski D. Qualitative and quantitative determination of main alkaloids of Chelidonium majus L. using thin-layer chromatographyc-densitometric method. Acta Chromatographica. 2017;3(29):385-97.

21. Sarkozi A, Janicsak G, Kursinszki L, Kery A. Alkaloid composition of Chelidonium majus L. studied by different chromatographic techniques. Chromatographia. 2006;63(S13):S81-6. doi: 10.1365/s10337-006-0728-7.

22. ICH. Validation of analytical procedures: text and methodology Q2. In: Guideline ICH harmonized tripartite, ed. International Conference on Harmonization of Technical Requirements for registration of pharmaceuticals for human use. Vol. R1. Geneva; 2005.

23. Segarra Moragues JG, Iriondo JM, Catalan P. Genetic fingerprinting of germplasm accessions as an aid for species conservation: a case study with Borderea chouardii (Dioscoreaceae), one of the most critically endangered Iberian plants. Ann Bot. 2005;96(7):1283-92. doi: 10.1093/aob/mci280, PMID 16230324.

24. Sigh J. Maceration, percolation and infusion techniques for the extraction of medicinal and Aroamtic plants. Trieste: International Centre For Science And High Technology; 2008. p. 71-9.

25. Fiedler E, Grossmann G, Kersebohm DB, Weiss G, Witte C. Ullmann's encyclopedia of industrial chemistry. Ullmann's Encyclopedia of Industrial Chemistry. Weinheim: Wiley-VCH Press; 2005.

26. Yap JY, Hii CL, Ong SP, Lim KH, Abas F, Pin KY. Quantification of carpaine and antioxidant properties of extracts from Carica papaya plant leaves and stalks. J Bioresour Bioprod. 2021;10(4):1-9.

27. Bribi N, Algieri F, Rodriguez Nogales A, Garrido Mesa J, Vezza T, Maiza F, Utrilla MP. Anti-nociceptive and anti-inflammatory effects of total alkaloid extract from Fumaria capreolata. Evid Based Complement Alternat Med. 2015;7:1-8. PMID 736895.

28. Vien DTH, Loc TV. Extraction and quantification of carpaine from carica papaya leaves of vietnam. Int J Environ Agric Biotechnol. 2017;2(5):2394-97. doi: 10.22161/ijeab/2.5.16. 